\title{
The light transmission and seiche depth of Izmir Bay, western Turkey
}

\author{
Erdem Sayin ${ }^{1}$, Sezgi Adalioglu ${ }^{2}$ and Canan Eronat ${ }^{3}$ \\ Dokuz Eylul University, Institute of Marine Sciences 8 Technology, Inciralti, 35340 Izmir, Turkey. \\ ${ }^{1}$ e-mail: erdem.sayin@deu.edu.tr \\ 2 e-mail: sezgi.aoglu@deu.edu.tr \\ 3 e-mail: canan.ozturk@deu.edu.tr
}

Izmir Bay is one of the most polluted estuaries in the whole Mediterranean Sea. The inner part of the Bay (Inner Bay) is heavily affected by domestic and industrial discharge. As a result of these loads, strong eutrophication occurs in the Inner Bay, which is temporally anaerobic. The ecologically sensitive approach of the local authorities during the last decade has given rise to a wide variety of monitoring and research studies on this bay. On the other hand, the municipality of Izmir started to operate wastewater treatment facilities since January 2000. The Institute of Marine Sciences and Technology - Izmir (IMST) with its research vessel R/V K Piri Reis has been conducting an intensive monitoring program since 1988 and especially during the recent few years. These investigations provide an opportunity for the evaluation of the performance of the wastewater treatment plant in terms of the change in the optical properties of Izmir Bay water in a positive manner. The turbidity values measured in these monitoring studies indicate that the values have changed drastically after January 2000. Their spatial variation indicates that the values decrease from the Inner Bay towards the Aegean Sea. The turbidity (light transmission) values are measured with an automatic CTD (conductivity, temperature and depth) system during each cruise. The seiche disc depth measurement is carried out only occasionally. The accuracy of the seiche disc depth is dependent on certain daylight conditions and depends on the operator. The seiche disc depth $\left(D_{s}\right)$ is an important parameter to estimate primary production of organic matter (hereafter called production). A relation between light transmission (turbidity) value and seiche disc depth $\left(D_{s}\right)$ is found with very good agreement. The correlations are very high (approximately 0.94) with slight seasonal variation.

\section{Introduction}

Izmir Bay is one of the largest bays in the western region of the Aegean Sea coast of Turkey. It is roughly ' $\mathrm{L}$ ' shaped with its entrance from the Aegean Sea at its north. According to the topographical, hydrological and ecological features, Izmir Bay is divided into three regions (Inner, Middle and Outer Bay). Outer Bay is divided into further three sub-regions (Outer-I, Outer-II and Outer-III; figure 1). The water properties of the bay are generally analyzed using the data from these different regions. Monitoring studies in Izmir Bay have been carried out by the Institute of Marine Sciences and Technology of Dokuz Eylül University with R/V K Piri Reis, Izmir since 1980. The important physical features based on observations and modeling studies were given by Sayin (2003). Unfortunately, there have been no previous studies relating the optical properties and turbidity of Izmir Bay. Therefore, this study is meant to be a pioneering work which studies the optical properties, i.e., light transmission and seiche disc depth of Izmir Bay.

Keywords. Light transmission; light intensity; seiche depth; Izmir Bay; correlation; attenuation coefficient. 


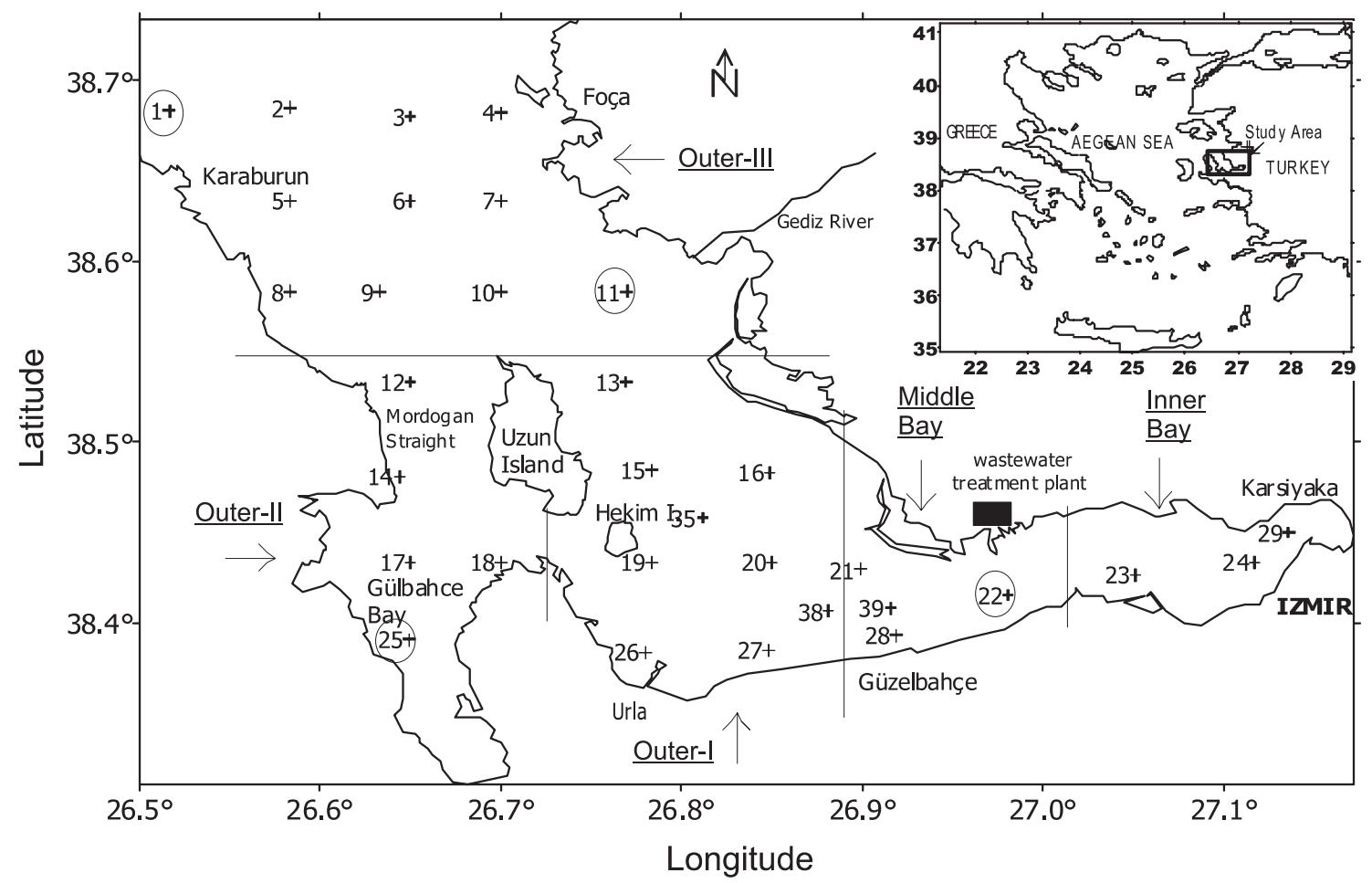

Figure 1. Locations of CTD stations in the Izmir Bay. Stations selected to identify optical parameter changes (stations 1 , 11, 22 and 25) are indicated in a circle.

During the past 30-40 years, Izmir Bay has been heavily influenced by anthropogenic pollution from the city of Izmir. This pollution (including domestic and industrial waste-water, urban runoff, ship ballast, sediment and contaminated waters of rivers and streams) has had significant adverse effect on the water quality of Izmir Bay. Bukata et al (1995) have analyzed the optical properties in natural waters. A part of their study deals with the relationship between the seiche depth and the hybrid property comprised, in part, by inherent optical property of the water column (c) and in part by an apparent optical property of the water column $\left(k_{d}\right)$. Bukata et al have found a very high correlation between the total attenuation coefficient $c$ and seiche depth $D_{s}$ for some locations at Great Lakes. Vladimirov et al (1999) have used seiche depth $D_{s}$ in certain depth ranges to estimate the bio-optical parameters, i.e., the mean value of beam attenuation coefficient and the mean value of vertical attenuation coefficient for the Black Sea. The correlation coefficients by their estimates are about 0.81 . Similar estimates have been made by several authors (Aas 1980 for the Norwegian coastal areas and Barents Seas, Sherstyankin et al 1988 for Lake Baikal and Kullenberg 1980 for the region of Peru up-welling) for different basins other than the Black Sea.

Hydro-optical properties of the Izmir Bay are investigated by using in situ measurements that were obtained from 1996 to 2005. There are very few CTD measurements in 1995 and no seiche disc measurement at all in 1994 and 1995 in the Bay. Seiche disc and the optical sensor (transmissometer) of a CTD system are used to measure water clarity. Seiche depth and light transmission values are strongly related to the turbidity of water. Therefore, there must be a high correlation between seiche depth and light transmission values. Such a relationship could be used to estimate unmeasured seiche depth using light transmission values seasonally and regionally.

In this study we try to estimate the unobserved seiche depth $D_{s}$ using light transmission values. The reason for this choice is that the light transmission values have been observed automatically using a transmissometer which is attached to the CTD frame since 1994 in the Izmir Bay. On the contrary, seiche depth measurements need an extra effort and they depend on the operator and the day light condition, i.e., zenith angle of the sun. Seiche depth information contains both the inherent and the apparent optical properties. On the other hand, the light transmission holds only the inherent optical property. Therefore the light transmission values can be used to calculate the inherent optical property of the water column (c) directly. To include the apparent optical property of the water column $\left(k_{d}\right)$ into our estimate (to find seiche depth from light transmission), an 
exponentially decreasing function of light transmission with depth is assumed in the equations.

This study is divided into six sections of which this introduction is the first. Sections two and three contain a description of the optical properties such as light transmission and seiche depth behaviors for Izmir Bay. Section four involves the mathematical formulation and a summary of the methods for finding an appropriate formulation for $D_{s}$. The computed results are represented in section five and the last section gives concluding remarks and summarizes the major findings of the study.

\section{Light transmission}

Light is one of the major energy sources of algae and some bacteria. Penetrating, scattering and absorption of light into the water vary with the characteristics of chemical, physical, biological contents of the water. Light intensity strongly affects the photosynthesis and biological growth, etc. In other words, organisms convert inorganic matter to organic matter and to organic compounds by capturing light energy. Light penetration and photosynthesis are much more effective in the upper water column than the lower. The depth into which a given intensity of light penetrates is a function of the transparency of the water and differential absorption by the water. Since differential absorption by the water is constant, the changes in the depth of effective light penetration are primarily due to particle concentration (Khorram et al 1991). Increased turbidity from the addition of excess suspended matter to water reduces light penetration and depresses growth (Clark 1977).

Izmir Bay is one of the most polluted estuaries in the whole Mediterranean Sea. The Inner Bay is heavily affected by domestic and industrial loads from the surrounding city amounting to ca. 5 million population equivalents (PE). As a result of these loads, strong eutrophication occurs in the inner sections of the bay that is temporally anaerobic (IMST-124 2001). Control of the discharge of wastewaters into the Middle Bay started since January 2000 through the two wastewater treatment plants. The treated water is being discharged into the Middle Bay from the sea surface.

A transmissometer (Alphatracka II) which is attached to the CTD frame measures the transmissivity. It has a modulated light source and a coherent detector. The distance between the light source and the detector is $10 \mathrm{~cm}$ (path length). This sensor measures the beam attenuation coefficient $(c)$. The beam attenuation coefficient includes both absorption and light scatter losses. The light transmission is a function of the beam attenuation coefficient.
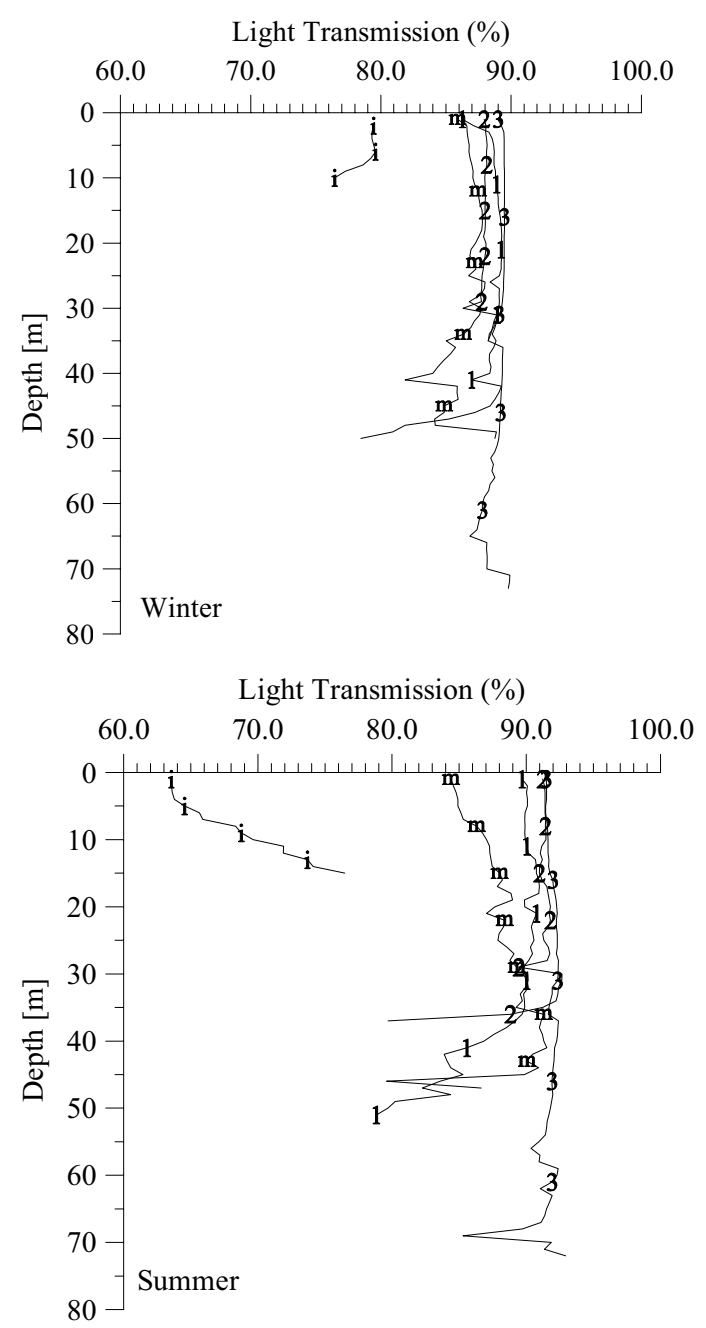

Figure 2. Vertical profiles of the average light transmission values of the different part of the Izmir Bay in winter (above) and summer seasons (i: Inner Bay, m: Middle Bay, 1: Outer-I, 2: Outer-II, 3: Outer-III).

Generally, the light transmission values (similar to the seiche depths) change seasonally in the three regions (Inner, Middle, and Outer) of Izmir Bay. During the summer, the Inner Bay is more turbid $(\sim 63 \%$, figure 2$)$ in the coastal zone. In winter, the inner bay surface light transmission values increase to $\sim 79 \%$, from the lower summer values $(\sim 63 \%$; figure 2)". The Middle Bay is only marginally more turbid than the Outer Bay during both winter and summer due to the coming surface current from the Aegean Sea. It enters into the Outer II through the narrow Mordogan Strait. The current intensity increases in the narrow channel. As a result of the strong surface current, counter strong bottom current occurs causing turbidity over the topography also in Gülbahce Bay. Therefore, the near-bottom turbidity values are sometimes higher in the Outer II compared to the values in Middle Bay in summer as well as in winter. Light transmission in Outer I is less than the value in Middle Bay because of the 

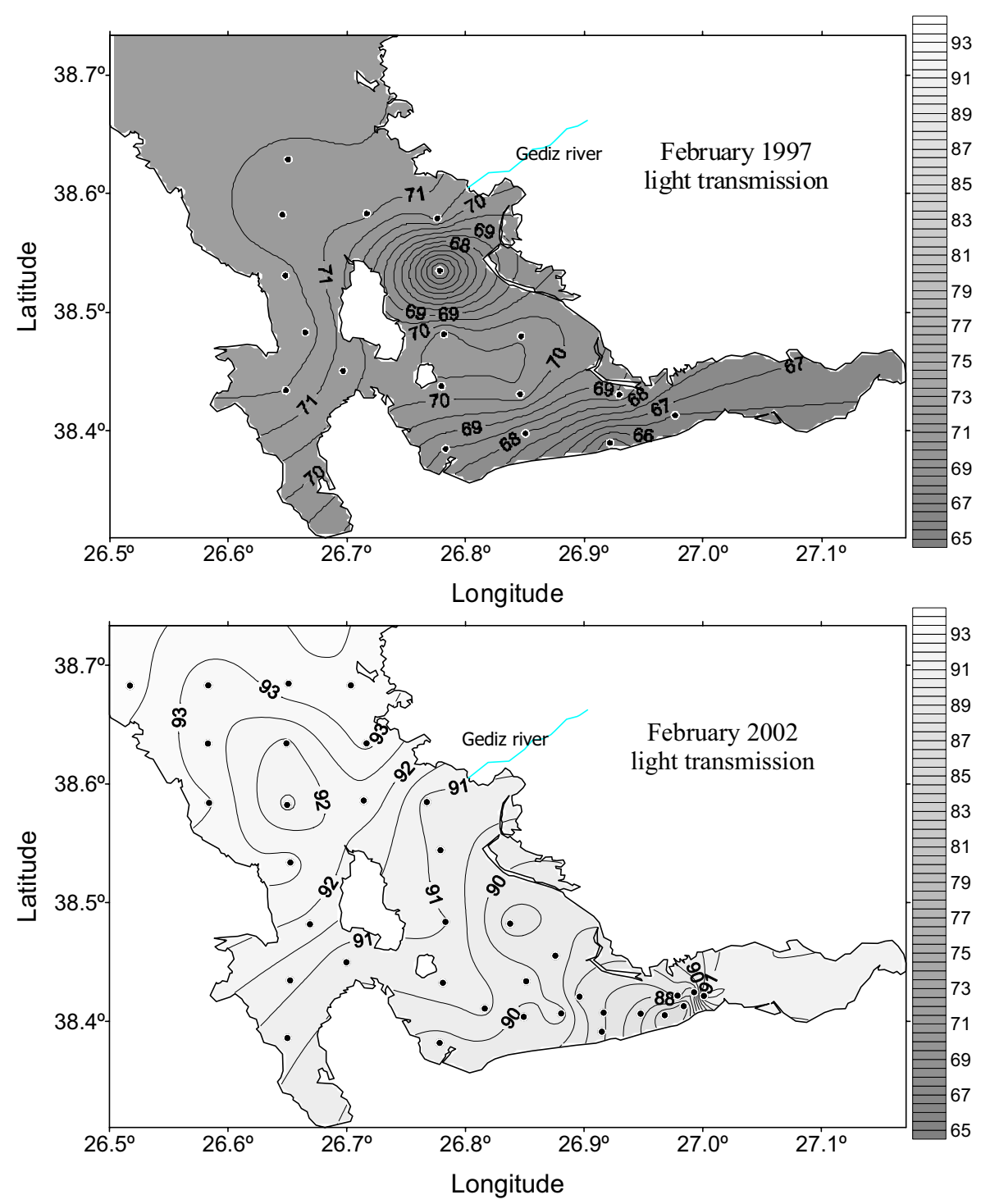

Figure 3. Winter distribution of surface light transmission before (above) and after 2000 in the Izmir Bay.

influences of both the sediment-rich surface water from Gediz River and the anticyclonic gyre formed under the influence of the dominant northerly wind over the Izmir Bay region. With the wind steering effect, most of the suspended material sinks to the lower layer in the core of anticyclonic middle gyre in Outer I. On the other hand, offshore values (towards the Aegean Sea) are slightly lower in the winter $(\sim 89 \%)$ than the summer values $(\sim 90.5 \%)$. In all seasons, the most turbid water takes place in the Inner Bay and the light transmission values increase gradually in the direction of the Aegean Sea. Horizontal light transmission pattern supports these regional differences. Figure 3 gives the winter 1998 and 2001 surface light transmission distributions in the Izmir Bay.

In January 2000, the municipality of Izmir has put the wastewater treatment facilities controlling the coastal discharge into Izmir Bay into operation.
The observations of light transmission before and after wastewater treatment indicate that water clarity has increased remarkably (figures 3 and 4). It is obvious that there has been a tremendous change in light transmission both in summer and winter. Surface light transmission values have changed from $\sim 70 \%$ to $\sim 85-90 \%$ in winter and also in summer in the recent $4-5$ years.

Some stations in the bay have been selected to identify any change that might occur in optical parameters after wastewater treatment. These stations are numbered as station 1 (reference station, Aegean Sea water), station 11 (Gediz river area), station 22 (this station is strongly influenced by wastewater treatment) and station 25 (in Gülbahce Bay).

The light transmission values of sub-surface and sub-bottom layers are shown in figure $5(\mathrm{a})$ and $5(\mathrm{~b})$ respectively. It is very obvious that the turbidity is 

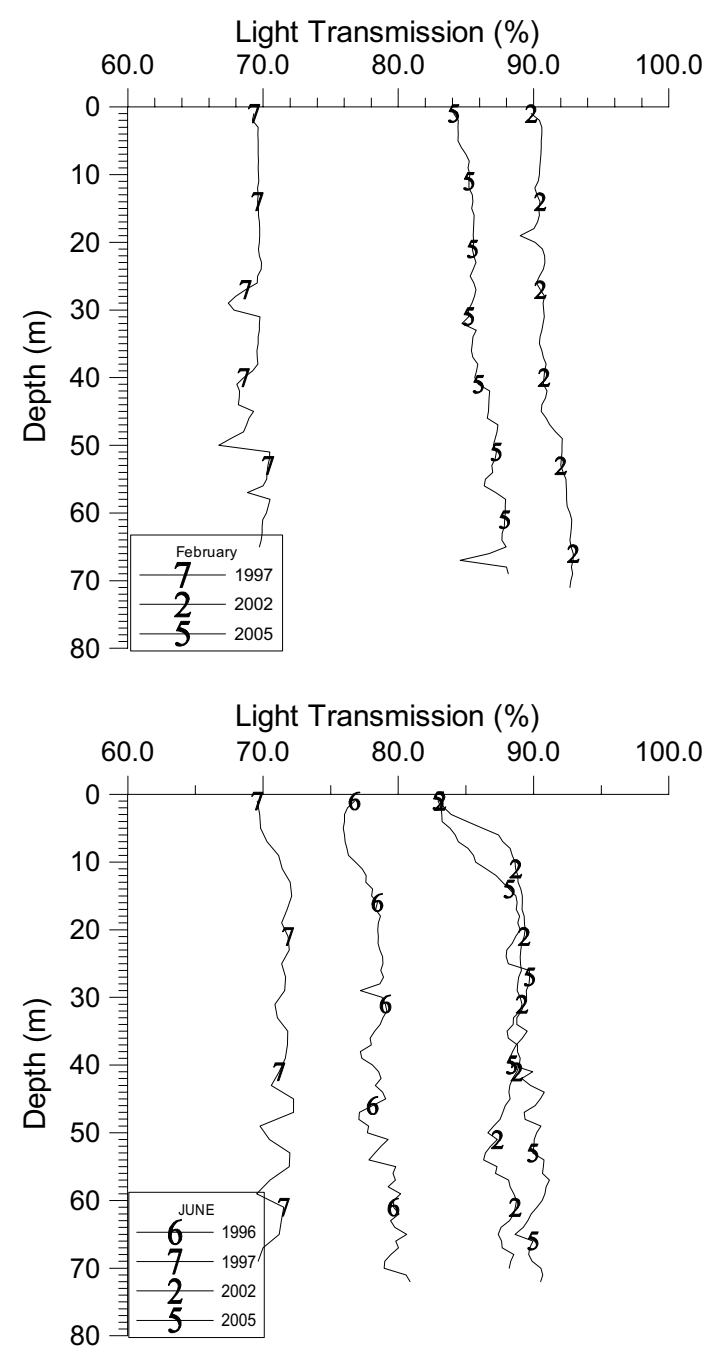

Figure 4. The average light transmission vertical profiles before and after 2000 in winter (above) and in summer in the Izmir Bay.

lower in the bay after January 2000 in all stations. This fact is apparent both from the light transmission values and from the seiche disc values. Due to insufficient seiche disk depth values at 1998-2000 on hand, the tremendous change which was seen in light transmission values cannot be shown at stations 22 and 25.

The Institute of Marine Sciences and Technology - Izmir had a project to monitor the Izmir Bay water quality in order to determine and understand the role of wastewater treatment plant in the quality of water in the Bay. As expected, the wastewater treatment plant contributes positively. This improvement is observed by the turbidity all over the area, from Inner to Outer III (figure 5a and $5 \mathrm{~b})$. The wastewater treatment plant has an influence on turbidity. However, improvement in water clarity has also been observed near the Aegean Sea (station 1). Continued improvement of the water clarity after 2000 at all depths and in all stations suggests that the improvements are not only due to the wastewater treatment, but may be due to natural influences in the Aegean Sea. It could be related to global scale climatic changes that took place but this factor needs further investigation. Man'kovskii and Solov'ev (2005) have mentioned about the variation of transparency in the Black Sea. They have found that the transparency (seiche disc depth) changes from 14.9-18.1 $\mathrm{m}$ in the 19701973 period to $6.2 \mathrm{~m}$ in 1992 and to about $10-12 \mathrm{~m}$ between 1997 and 2002. They have made a comment about the change observed in 1992: "It is due to the influence of anthropogenic and natural factors, the marine ecosystem has suffered significant changes which have resulted in a decrease in the transparency of waters while their productivity improved. Change in ecosystem affects the composition of the suspension, which leads, in particular, to changes in the characteristics of the indices of scattering of light".

The water from the Aegean Sea (station 1) flows generally through the Mordogan Passage into the Gülbahce Bay (station 25). Therefore, the slope of the time-dependent light transmission curve decreases gradually in both station 1 and station 25 until year 2000. The rise and fall in the light transmission values of station 22 (water treatment plant) after 2000 may be attributed to the temporal variations in the effectiveness of the wastewater treatment.

\section{Seiche depth}

The seiche disc is simply a flat circular plate 20 $30 \mathrm{~cm}$ in diameter, either all white or with two quadrants painted black and two painted white. It is lowered through the water column in a horizontal attitude until it is observed to just disappear. The depth at which this happens is called the seiche depth. It is widely used for the determination of water clarity. The seiche depth $D_{s}$ is related to optical parameters of the water column including attenuation length, optical depth, beam attenuation coefficient $(c)$, irradiance attenuation coefficient $\left(k_{d}\right)$, scattering albedo, and the forward scattering and backscattering coefficients (Bukata et al 1995). Seiche depth, $D_{s}$, is generally expressed in meters, and is used to provide a quantitative estimate of the optical property $\left(c+k_{d}\right)$. Seiche depths change regionally and seasonally in the Izmir Bay. They change from $1-2 \mathrm{~m}$ in the Inner Bay to $28-29 \mathrm{~m}$ in the Outer III region of the Outer Bay. The Inner Bay, Middle Bay and the Gediz River estuary at the northeastern outer bay have more turbid water than the other regions. The turbidity patterns are under the influence of current, especially wind-induced. The less turbid 

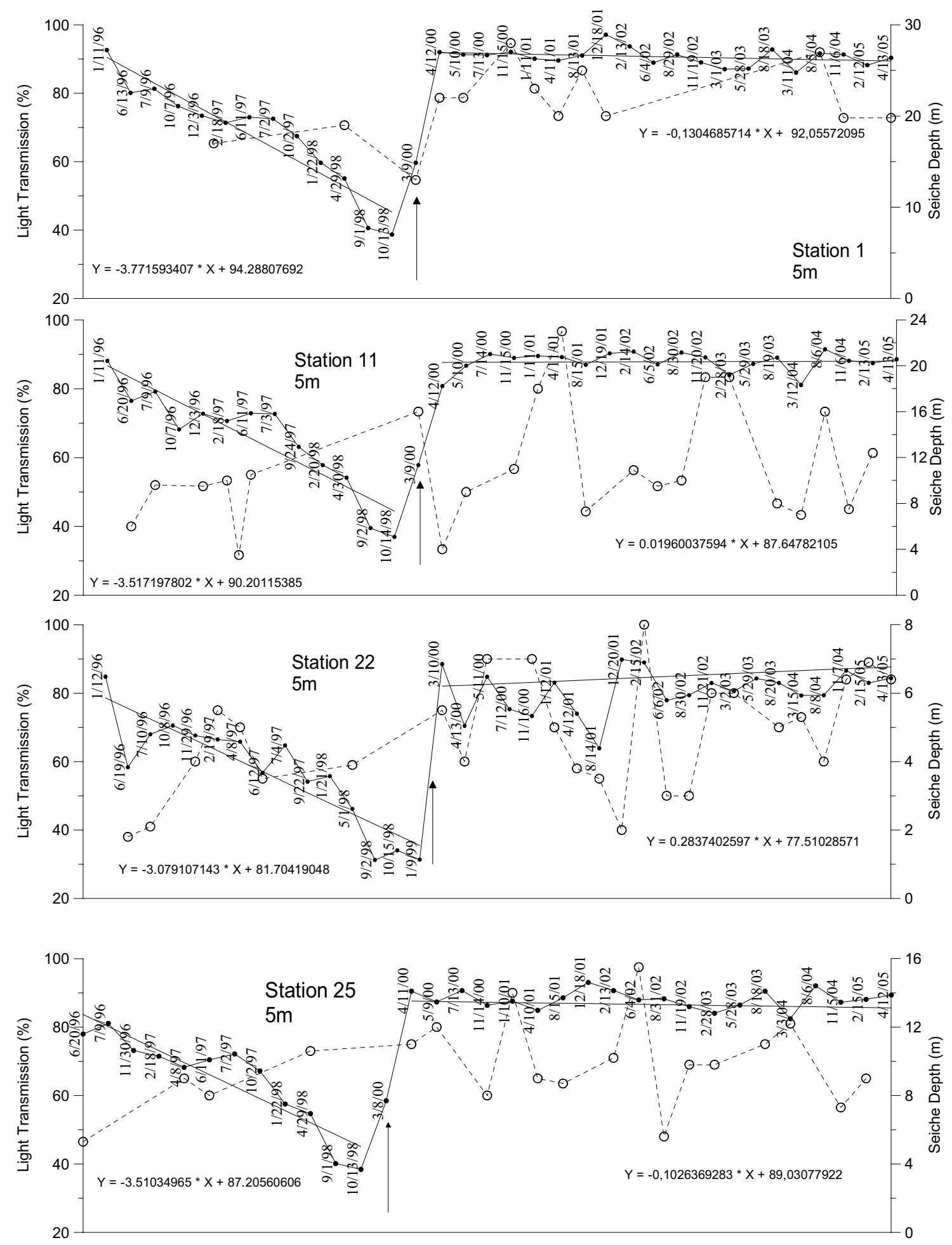

Figure 5(a). The light transmission (solid lines) values changing with time (surface water, $5 \mathrm{~m}$ ). Light transmission trend lines were drawn. Time series of seiche disc depth (dashed lines) values at the same stations were drawn on the same plot (on a second y-axis). The arrow that is placed on the figures shows the time when the water treatment was initiated (January 2000).

water forms near the Aegean Sea and also in the gyre formed at the Outer I. Seiche disc depth increases after 2000 in a similar manner to light transmission. The seiche disc results of both winter seasons February 1997 and February 2002 indicate that the seiche depth values change especially in the Inner Bay, Middle Bay and in the Outer I from one winter to another (figure 6). The reduced turbidity, measured by seiche disc depth, can also be observed during the summer (figure 7 ). 

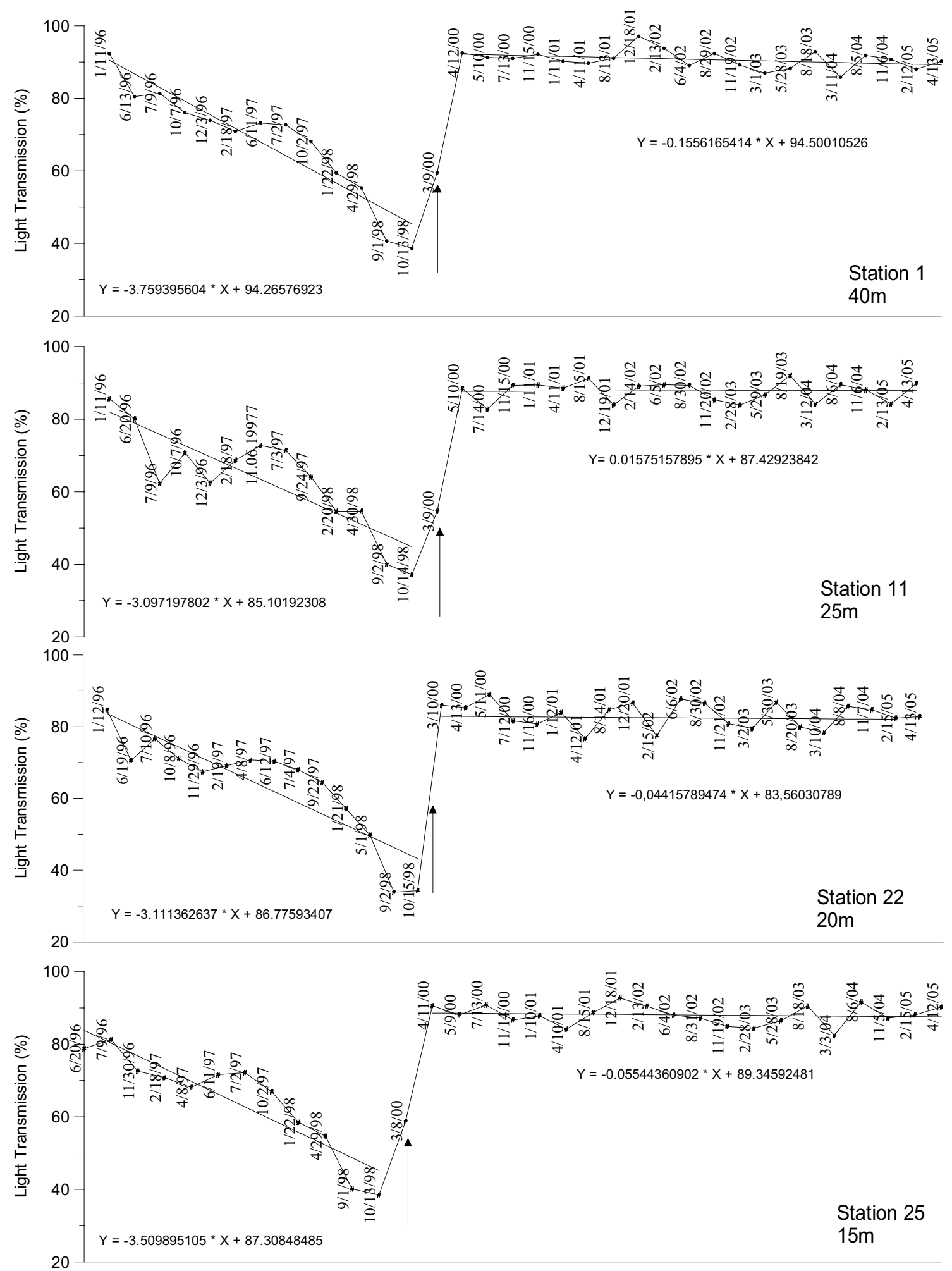

Figure 5(b). The light transmission values changing with time (near bottom). The arrow that is placed on the figures shows the time when the water treatment was initiated (January 2000).

\section{Relation between light transmission and seiche disc depth}

In this section, a relation between the seiche disc depth and the exponential integral sense of light transmission is presented. Thus, the seiche disc depth values that were measured in the last four cruises can be estimated from the measured light transmission data as if they were not observed and compared with the observed values. The data set 

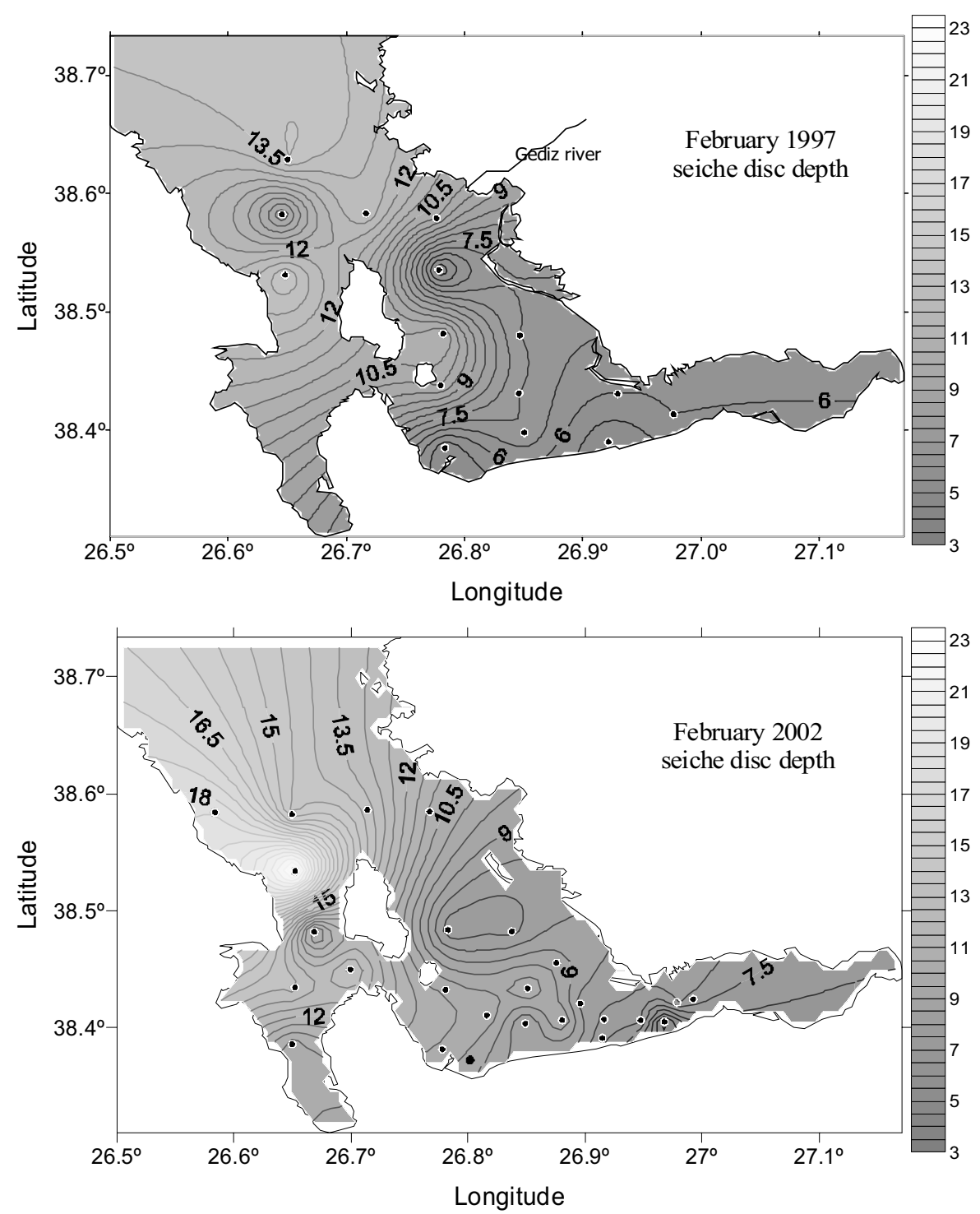

Figure 6. The seiche depth distributions for February 1997 (top) and 2002 (bottom) in the Izmir Bay. The locations of stations are shown as black dots.

contains 695 seiche disc measurements and over 45,000 light transmission and beam attenuation coefficient values. They were obtained from the cruise data measured in the stations shown in figure 1. This enables an estimate of seasonal and spatial variability of seiche depth in the bay by evaluating the cruise light transmission data.

When light propagates through water, its intensity decreases exponentially with depth. In this study, the exponential loss of intensity (attenuation) is taken into account for the calculation of the seiche depth as a function of light transmission. Attenuated light is called 'downwelling irradiance attenuation of light' that is a consequence of the absorption and scattering process. Absorption involves the conversion of electromagnetic energy into other forms (usually heat or chemical energy). The absorbers in seawater are: algae using light as a source of energy for photosynthesis, inorganic and organic particulate matter in suspension, dissolved organic compounds and the water itself. Scattering is simply defined as the changes in the direction of the electromagnetic energy, as a result of multiple reflections from suspended particles.

Irradiance attenuation is described in terms of irradiance attenuation coefficient $k_{d}$, which is an apparent optical property. When the photons comprise a beam of light, the attenuation is described in terms of the beam attenuation coefficient $c$, which is an inherent optical property (Bukata et al 1995).

The reduction of light in the water column can be expressed in terms of the diffuse attenuation coefficient, $k_{d}$ (related to the downward irradiance);

$$
I_{d}=I_{0} \cdot e^{-k_{d} d}
$$



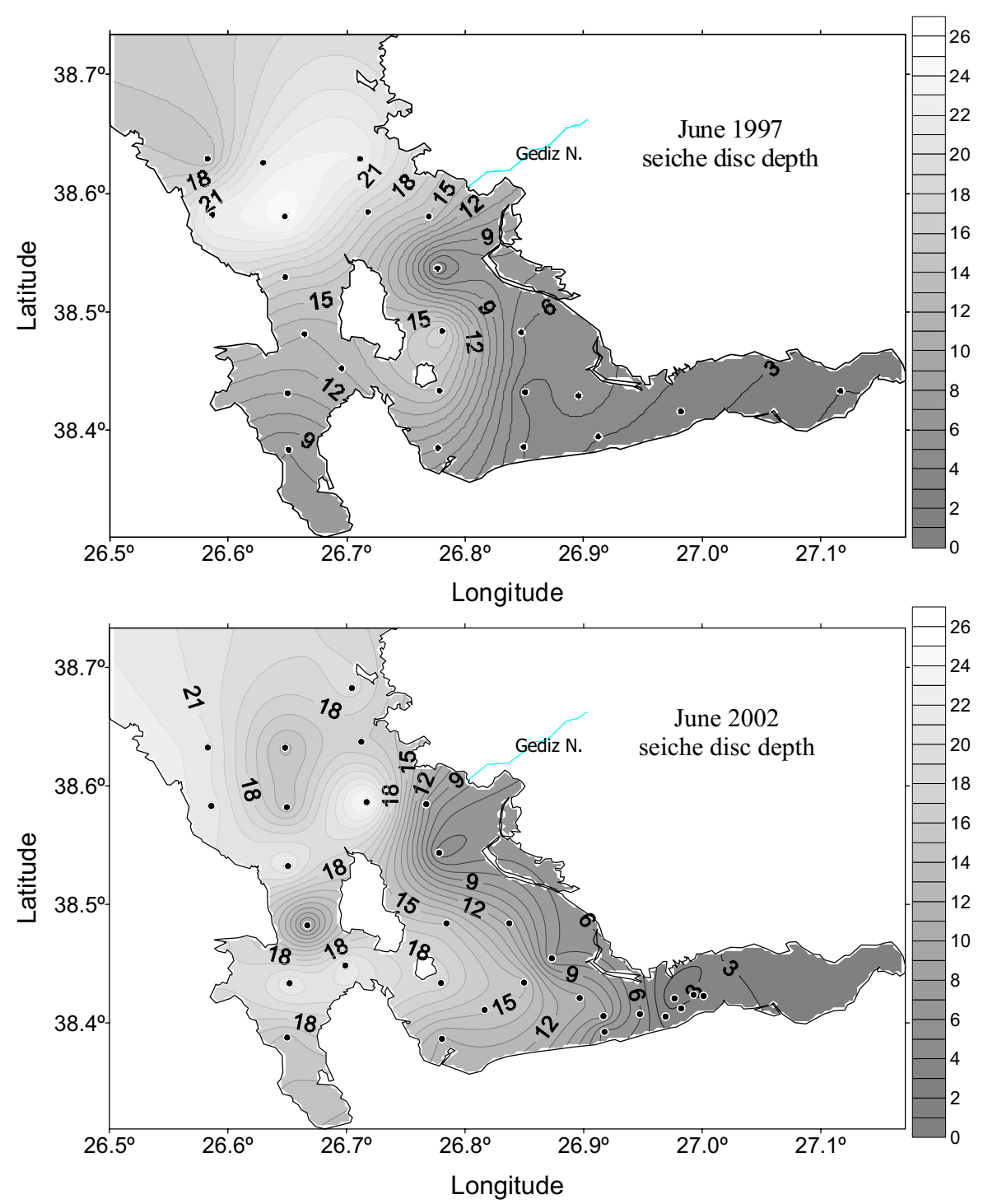

Figure 7. The seiche depth distributions for June 1997 (top) and 2002 (bottom) in the Izmir Bay.

where $I_{0}$ is the incident light intensity, $I_{d}$ the light intensity traveling distance of $(d)$ (Khorram et al 1991). The diffuse attenuation coefficient $\left(k_{d}\right)$ is an apparent optical property, because it depends both on the medium and on the directional structure of the surrounding light field.

The beam attenuation coefficient in the water column can be defined as follows:

$$
k=k_{w}+k_{p}+k_{s},
$$

where $k_{w}, k_{p}$ and $k_{s}$ are possible diffusion and scattering of light energy due to water $(w)$, suspended particles $(p)$ and dissolved matter $(s)$, respectively (Bukata et al 1995). In some literatures authors prefer to use $c$ instead of $k$, which is equal to:

$$
c=a+b,
$$

where $a$ is absorption and $b$ is light scatter losses.
There are two approaches (direct and indirect) to estimate the average diffuse attenuation coefficient $\left(k_{d}\right)$ in a given water column. The direct approach involves the actual measurements of light intensity at different depths using a suitable sensor; then the diffuse attenuation coefficient can be calculated using equation (1).

The indirect estimation can be done from seiche reading $\left(D_{s}\right.$, in meter), using an empirical relation, originally proposed by Poole and Atkins (1929) as follows:

$$
k_{d}=\frac{1.7}{D_{s}}
$$

However, these theoretical equations are not always applicable for practical purposes, because they require information about the angular distribution of radiation field, which is difficult to measure. 
Table 1. The number of observations for each cruise and correlation coefficients related to the relationships between seiche depths $\left(D_{s}\right)$ and the sum of light transmission values.

\begin{tabular}{|c|c|c|c|c|c|}
\hline $\begin{array}{l}\text { Cruise date } \\
\text { (month, year) }\end{array}$ & $\begin{array}{c}\text { No. of stations } \\
\text { (observations) } \\
\text { seiche disc } \\
D_{s} \\
\end{array}$ & $\begin{array}{c}\text { No. of stations } \\
\text { light } \\
\text { transmission } \\
L T\end{array}$ & $\begin{array}{c}\text { No. of } \\
\text { observations } \\
\text { light } \\
\text { transmission }\end{array}$ & $\begin{array}{l}\text { No. of } \\
\text { common } \\
\text { stations } \\
D_{s}+L T \\
\end{array}$ & $\begin{array}{c}\text { Correlation } \\
\text { coefficient } \\
R\end{array}$ \\
\hline January 1996 & - & 19 & 877 & - & - \\
\hline June 1996 & 14 & 37 & 1381 & 14 & 0.910 \\
\hline July 1996 & 21 & 21 & 802 & 21 & 0.989 \\
\hline September 1996 & 18 & - & - & - & - \\
\hline October 1996 & 20 & 20 & 744 & - & - \\
\hline November 1996 & 6 & 24 & 978 & 6 & - \\
\hline January 1997 & 27 & - & - & - & - \\
\hline February 1997 & 15 & 18 & 637 & 15 & 0.854 \\
\hline April 1997 & - & 10 & 117 & - & - \\
\hline June 1997 & 21 & 22 & 852 & 21 & 0.923 \\
\hline July 1997 & - & 39 & 1620 & - & - \\
\hline September 1997 & - & 23 & 1092 & - & - \\
\hline October 1997 & - & 10 & 399 & - & - \\
\hline January 1998 & - & 30 & 1252 & - & - \\
\hline April 1998 & 15 & 30 & 1211 & 15 & 0.905 \\
\hline September 1998 & - & 31 & 1229 & - & - \\
\hline October 1998 & - & 29 & 1186 & - & - \\
\hline January 1999 & - & 7 & 232 & - & - \\
\hline March 2000 & - & 37 & 1315 & - & - \\
\hline April 2000 & 35 & 52 & 1370 & 35 & 0.932 \\
\hline May 2000 & 32 & 34 & 1153 & 32 & 0.987 \\
\hline July 2000 & - & 35 & 1291 & - & - \\
\hline November 2000 & 14 & 36 & 1277 & 14 & 0.900 \\
\hline January 2001 & 22 & 41 & 1388 & 22 & 0.978 \\
\hline April 2001 & 28 & 34 & 1172 & 28 & 0.914 \\
\hline August 2001 & 25 & 31 & 1184 & 25 & 0.920 \\
\hline December 2001 & 19 & 31 & 1299 & 19 & 0.993 \\
\hline February 2002 & 25 & 34 & 2750 & 25 & 0.961 \\
\hline June 2002 & 30 & 34 & 1279 & 30 & 0.864 \\
\hline August 2002 & - & 33 & 1303 & - & - \\
\hline November 2002 & 31 & 40 & 1468 & 31 & 0.929 \\
\hline March 2003 & 33 & 41 & 1337 & 33 & 0.969 \\
\hline August 2003 & 25 & 40 & 1390 & 25 & 0.936 \\
\hline March 2004 & 40 & 31 & 1488 & 40 & 0.940 \\
\hline August 2004 & 43 & 59 & 1593 & 43 & 0.962 \\
\hline November 2004 & - & 54 & 2225 & - & - \\
\hline February 2005 & 36 & 51 & 1476 & 36 & \\
\hline April 2005 & 32 & 47 & 1521 & 32 & \\
\hline June 2005 & 36 & 48 & 1636 & 36 & \\
\hline September 2005 & 32 & 42 & 1374 & 32 & \\
\hline
\end{tabular}

According to Idso and Gilbert (1974), the constant (1.7) always gives fairly close extinction coefficients when compared to optically measured coefficients in a wide range of water visibility (turbid to clear ocean water) covering $D_{s}$ between 1.9 and $35 \mathrm{~m}$ (Parsons et al 1994).
The seiche disc is a simple equipment for the measurement of water clarity. The seiche depth $\left(D_{s}\right)$ can be used to estimate visibility, attenuation coefficient and the depth of photic zone by applying simple empirical formulas. It is possible to gain information about biological activities using 

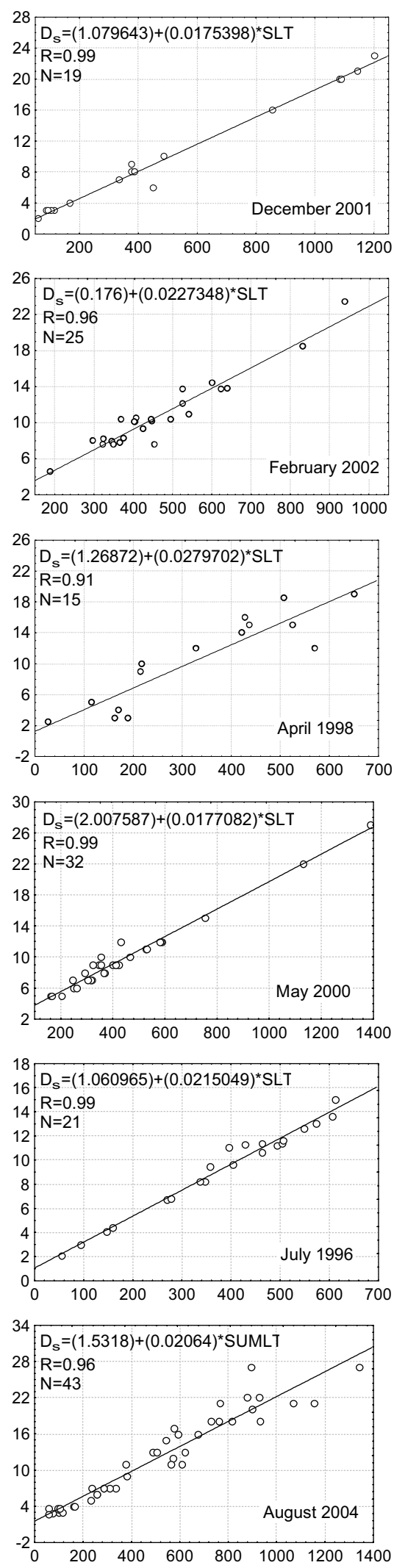
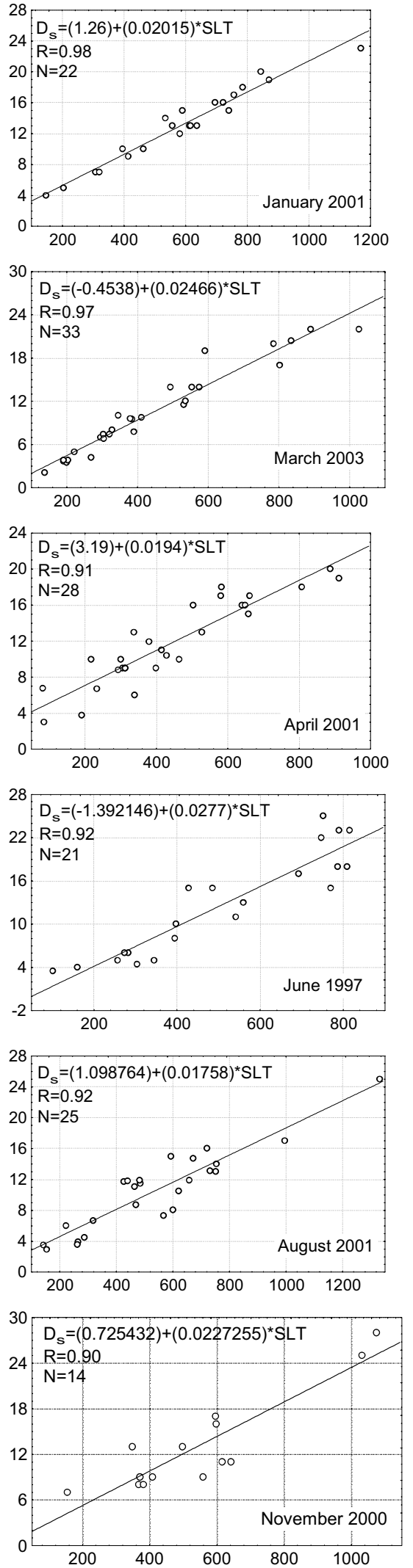
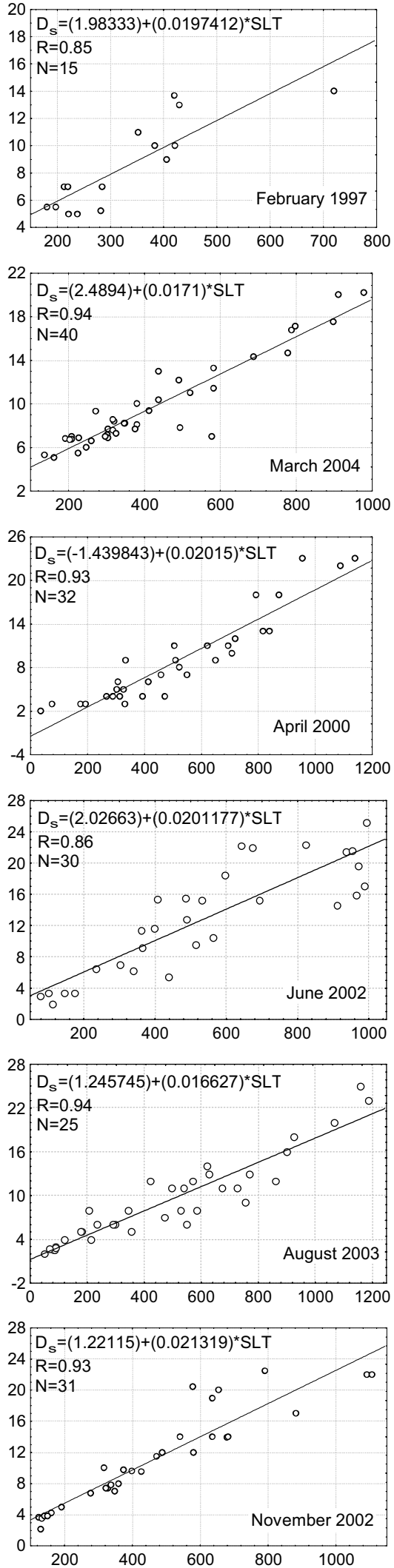

Figure 8. The regression results showing agreement between the seiche disc and the light transmission values. 
Table 2. The $c_{1}$ and $c_{2}$ values are the coefficients in equation (4) $\left(D_{s}=c_{1}+c_{2} \cdot S L T\right)$.

\begin{tabular}{lcc}
\hline Season & $c_{1}$ & $c_{2}$ \\
\hline Winter & 1.01695 & 0.02026 \\
Spring & 1.17298 & 0.02041 \\
Summer & 1.09193 & 0.02022 \\
Autumn & 1.06693 & 0.02176 \\
\hline
\end{tabular}

seiche disc measurements together with remotely sensed data. One of the purposes of this study is to find a relation between in situ light transmission and seiche depth considering the apparent and also the inherent optical properties of the water based on data sets collected from 1996 to 2004. The light transmission measurements give information only about inherent water properties. However, the seiche disc depth measurements consider not only inherent $(c)$ but also apparent $\left(k_{d}\right)$ water properties. To gain apparent properties for light transmission, the exponential decrease of light transmission values with depth is assumed. An empirical formula has been obtained giving a relation between the sum of exponentially decreasing light transmission and the observed seiche depth value. In this
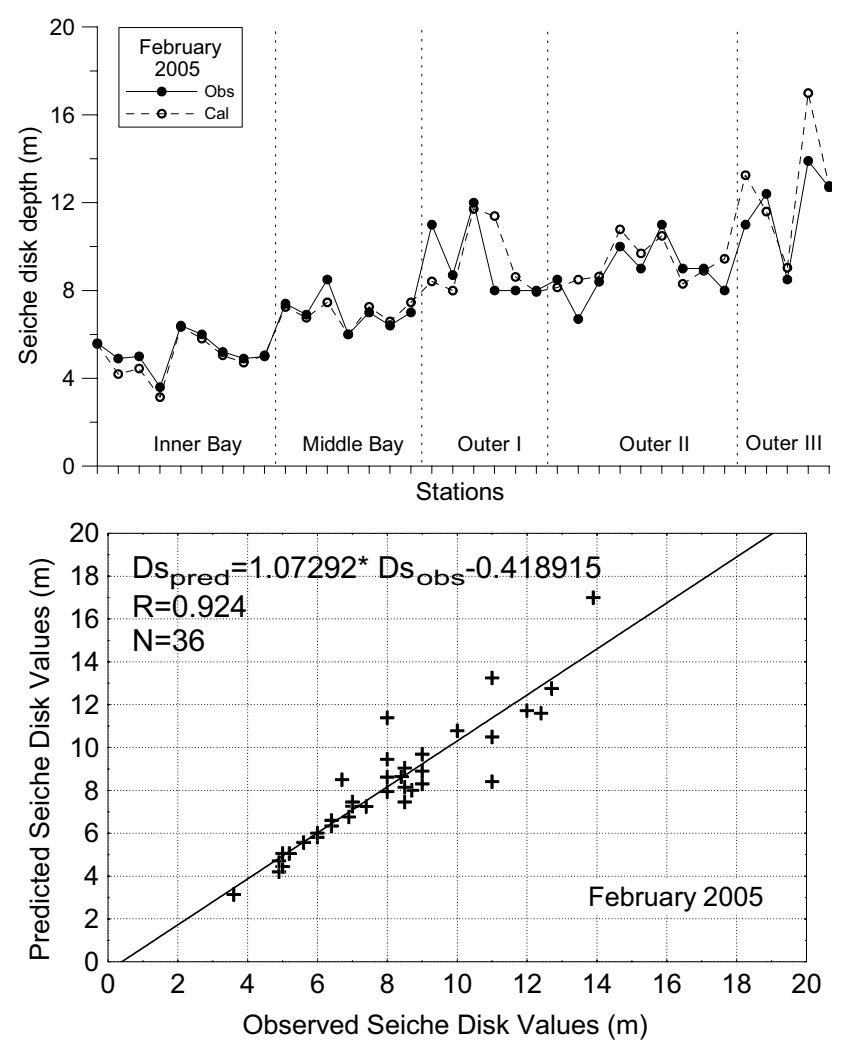

Figure 9(a). The comparison between measured and calculated seiche disc values for every station from Inner Bay to Outer III (above), the observed vs. the calculated values (below) for February 2005. formula the observed seiche depth values from 1994 to 2004 are used to calculate diffuse attenuation coefficient $k_{d}$ with the help of equation (3). A linear model is developed using the result of regression analysis between the observed seiche disc depth values and the sum of exponentially decreasing light transmission for each cruise. The correlation coefficients are given in table 1 . The obtained coefficients of model for each cruise are averaged seasonally to find a relationship between measured and unmeasured seiche disc depth values. Thus, light transmission values can be used in order to find unmeasured seiche disc depth values. This step will be explained in the next section in detail.

\section{Validation and implementation of model}

The relation between seiche disc depth and sum of light transmission values is assumed to be linear. A linear regression formula is:

$$
D_{s}=c_{1}+c_{2} \cdot S L T,
$$

where $S L T$ is the sum of the light transmission values determined assuming that the light transmission values decrease with depth as:
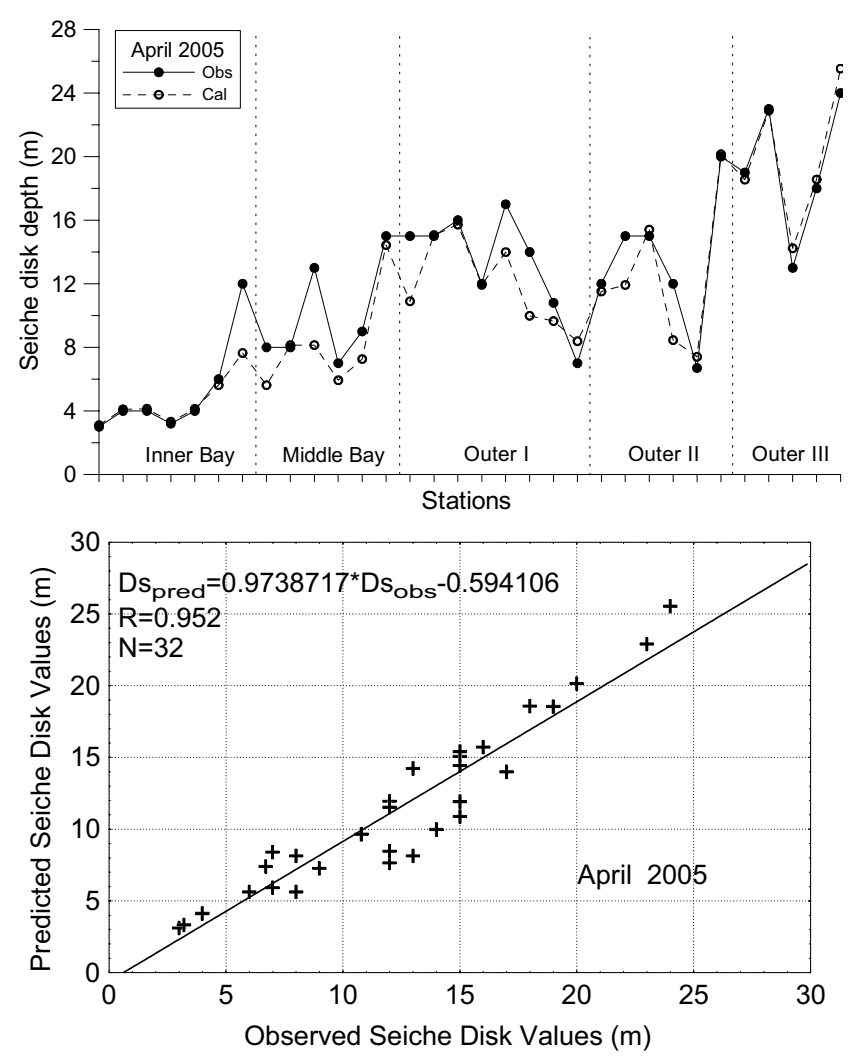

Figure 9(b). Same as figure 9(a), but for April 2005. 

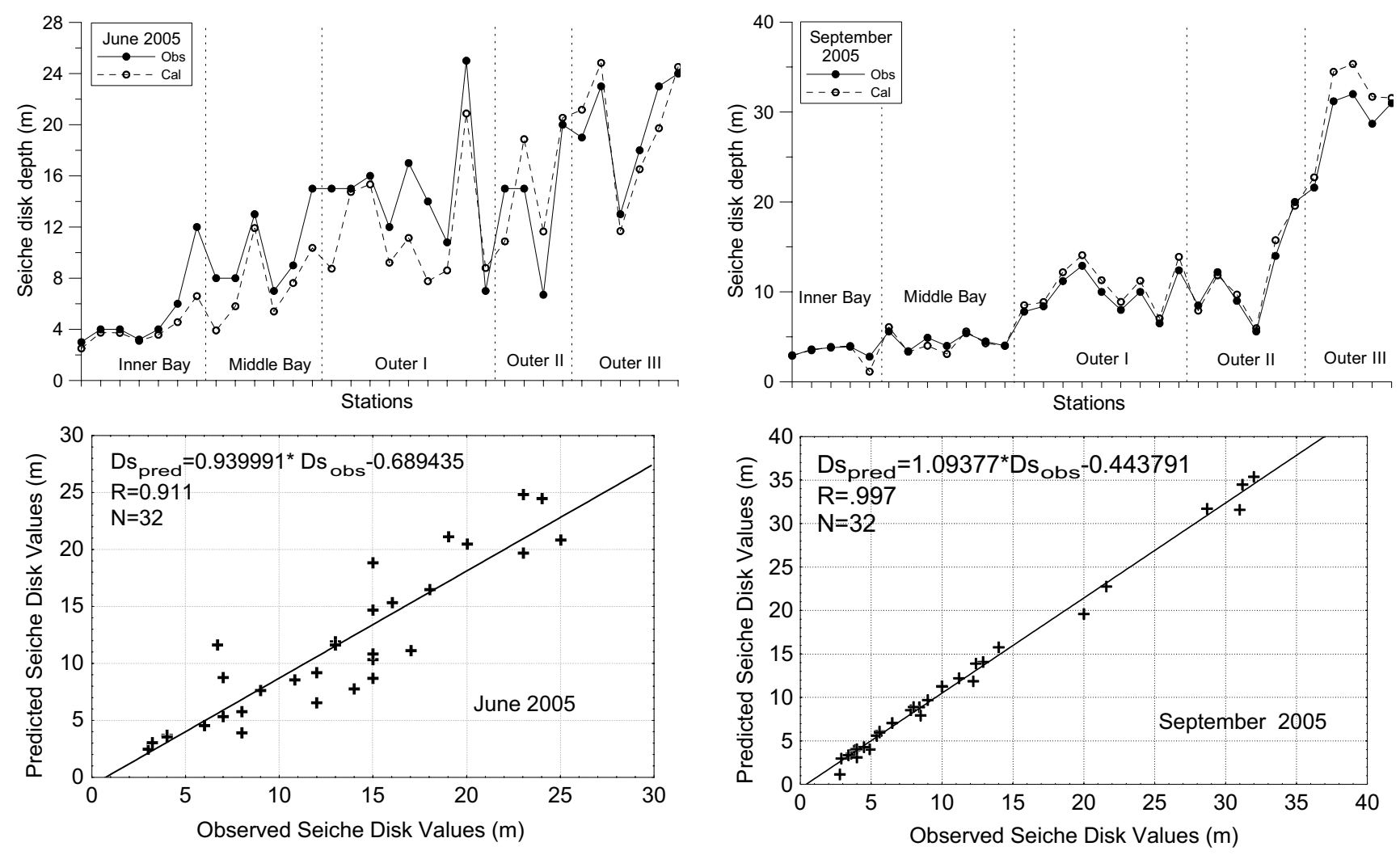

Figure 9(c). Same as figure 9(a), but for June 2005.

$$
S L T_{=} \sum_{d=0}^{d=D} L T_{d} e^{-k_{d} \cdot d},
$$

where $D$ is the depth of the water column. The diffuse attenuation coefficient $\left(k_{d}\right)$ is estimated from the average seiche depth values using equation (3). The number of observations for each cruise and the results of regression between observed seiche disc depth and the sum of exponentially decreasing light transmission values are summarized in table 1 and figure 8 . The coefficients, which were obtained as a result of regression analysis, are grouped seasonally (table 2 ).

After the seasonal models are improved, they are applied on the light transmission data of year 2005 (February, April, June and September) to estimate the seiche disc depths for these months. The calculated and observed seiche disc values are compared with each other (figure 9). Correlation coefficients obtained are shown in table 3.

Similar regression analysis is applied to find a model for every season. The new measured seiche depth values are compared with the values calculated using the readily developed regression model. Correlation coefficients obtained are very high: the variations are in the range $0.911-0.997$. As a result, it can be concluded that the model is able to estimate the seiche disc values only using in situ light transmission and historical data set.

Figure 9(d). Same as figure 9(a), but for September 2005.

Table 3. Using the model coefficients from table 2, the correlation coefficient shows the correlation between the measured and the predicted seiche disc values.

\begin{tabular}{lc}
\hline Cruise & $\begin{array}{c}\text { Correlation } \\
\text { coefficient }\end{array}$ \\
\hline February 2005 & 0.924 \\
April 2005 & 0.952 \\
June 2005 & 0.911 \\
September 2005 & 0.997 \\
\hline
\end{tabular}

Figure 9 shows the regression curves between the measured and calculated seiche depth values for winter. The correlation will be better when more data are adapted to the model. Table 2 shows the model coefficients obtained from the light transmission and the calculated seiche disc values for every season in the bay. The value $c_{1}$ of $c_{2}$ in equation (4) slightly changes seasonally.

\section{Discussion and conclusion}

The turbidity in Izmir Bay is analyzed using light transmission and seiche disc depth values. Although the observed seiche disc depth and also light transmission values vary seasonally, they show 
a tendency to increase from the Inner to Outer Bay indicating that more turbid water exists in the Inner Bay environment. Increasing values are also observed in time domain. After wastewater treatment, controlled surface discharge has started into the Middle Bay since January 2000. It is very obvious both from the light transmission values and also from the seiche disc values that the turbidity has been removed generally from the Bay after January 2000. The wastewater treatment plant has an influence on turbidity. However, improvement in water clarity has also been observed near the Aegean Sea (station 1). Continued improvement of the water clarity after 2000 at all depths and in all stations suggests that the improvements are not only due to the wastewater treatment, but might have improved due to natural influences in the Aegean Sea.

The other aim of this study is to find an equation to estimate the seiche depth from the light transmission data. Seiche disc, which depends on the combination of inherent and apparent optical water parameters, is an important tool to estimate primary production. This estimation can be compared with the estimation obtained from remote sensing data. An exponential function and summation of light transmission values were used in order to satisfy the inherent and apparent optical properties of water. As a result, we have found very high correlation between the in situ and calculated seiche depth values using light transmission values. The correlation coefficients vary from 0.911 to 0.997 . This result means that it is possible to make an estimate of seiche depth using historical light transmission values after adapting attenuation coefficient, $k_{d}$ in the model. Then the model is also able to give information about the seasonal variation of seiche depth using seasonal light transmission data that were already measured during cruises.

Sometimes seiche depth measurement could be more difficult because of occasional occurring of shallow pycnocline. In these cases, the formula found in this study can be used to obtain the seiche disc depth by estimating the depth of photic zone rather than the in situ one.

\section{Nomenclature}

$I_{d}$ : light intensity traveling distance of $d$

$I_{0}$ : incident light intensity

$k_{d}:$ diffuse attenuation coefficient

$k$ : beam attenuation coefficient

$k_{w}$ : possible diffusion and scattering of light energy due to water

$k_{p}$ : possible diffusion and scattering of light energy due to suspended particles $k_{s} \quad$ : possible diffusion and scattering of light energy due to dissolved matter

$D_{s} \quad$ : seiche depth

$R \quad$ : regression coefficient

$L T$ : observed light transmission value

$S L T$ : sum of light transmission values

$L T_{d}$ : light transmission values at the depth

$c \quad$ : beam attenuation coefficient

a : absorption coefficient

$b \quad$ : scattering coefficient

$c_{1}, c_{2}$ : model coefficients

\section{Acknowledgements}

This work was carried out in the framework of the Izmir Bay Marine Research Project. The authors acknowledge IMST/DEU for supporting the R/V K Piri Reis during the cruises. Grateful thanks are due to Prof. Dr Deniz Unsalan for valuable discussions and suggestions. And special thanks to Cetin Basoz who helped us by kindly allowing us to use the data base. We also extend our thanks to the people who participated in the cruises.

\section{References}

Aas E 1980 Relations between total quanta, blue irradiance and seiche disk observations; In: Studies in Physical Oceanography. Papers dedicated to Professor Nils $G$ Jerlov in commemoration of his seventieth birthday. Rep. Dept. Phys. Oceanogr., Univ. Copenhagen 42 11-27.

Bukata R P, Jerome J H, Kondratyev K Y and Pozdnyakov D V 1995 Optical Properties and Remote Sensing of Inland and Coastal Waters; CRC Press Inc, New York.

Clark J 1977 Coastal Ecosystem Management; John Wiley \& Sons, New York.

Idso S B and Gilbert R G 1974 On the universality of the Poole and Atkins seiche disc - light extinction equation; J. Appl. Ecol. 11 399-401.

IMST-124 2001 Marine research in the Izmir Bay project. Final Report. Institute of Marine Sciences and Technology, Izmir, Turkey, 260 p.

Khorram S, Cheshire H, Geraci A L and Rosa G L 1991 Water Quality Mapping of Augusta Bay, Italy from Landsat-TM Data. Int. J. Remote Sensing 12/4 803-808.

Kullenberg G 1980 Relationships between optical parameters in different oceanic areas; Rep. Ins. Fer Fysisk Oceanografi Kobenhavns Universitet, Copenhagen, No. $4257-79$.

Man'kovskii V I and Solov'ev M 2005 Indicatrices of scattering of light and the composition of suspension in the Black Sea; Phys. Oceanogr. 15(1) 57-70.

Parsons T R, Takahaski M and Hargrave B 1994 Biological Oceanographic Process; 3rd edn. Pergamon Press.

Poole H H and Atkins W R G 1929 Photo-electric measurements of submarine illumination throughout the year; J. Mar. Siol. Assoc. 16 297-324.

Sayin E 2003 Physical features of the Izmir Bay; Cont. Shelf Res. 23 957-970. 
Sherstyankin P P, Bbondarenko N A, Stepanova V V, Tarasova E N and Shur L A 1988 Interrelation between the beam attenuation coefficient and hydrophysical and biological indexes of the Baikal water, Optics of sea and atmosphere. Theses of rep. of 10 plenary of WG "Ocean optics" 223-224, Leningrad (in Russian).
Vladimirov V, Man'kovskii V I, Besiktepe S, Solov'ev M and Mishonov A 1999 Hydro-optical studies of the Black Sea: History and Status; In: Environmental Degradation of the Black Sea: Challenges and Remedies (eds.) Besiktepe S T, Unluata U, Bologa A S (Dordrecht: Kluwer Academic Publishers) NATO Science Series, 245-256.

MS received 24 February 2006; revised 30 June 2006; accepted 1 August 2006 